Published in final edited form as:

Blood Cells Mol Dis. 2017 March ; 63: 15-20. doi:10.1016/j.bcmd.2016.11.009.

\title{
GNPAT p.D519G is independently associated with markedly increased iron stores in HFE p.C282Y homozygotes
}

\author{
James C. Barton ${ }^{1,2}$, Wen-pin Chen ${ }^{3}$, Mary J. Emond ${ }^{4}$, Pradyumna D. Phatak ${ }^{5}$, V. Nathan \\ Subramaniam $^{6,7}$, Paul C. Adams ${ }^{8}$, Lyle C. Gurrin ${ }^{9}$, Gregory J. Anderson ${ }^{6,10}$, Grant A. \\ Ramm $^{6,7}$, Lawrie W. Powell ${ }^{6,7,11}$, Katrina J. Allen ${ }^{12}$, John D. Phillips ${ }^{13}$, Charles J. Parker ${ }^{14}$, \\ Gordon D. McLaren ${ }^{15,16}$, and Christine E. McLaren ${ }^{17}$ \\ ${ }^{1}$ Southern Iron Disorders Center, Birmingham, Alabama, 35209 USA \\ ${ }^{2}$ Department of Medicine, University of Alabama at Birmingham, Birmingham, Alabama, 35294 \\ USA \\ ${ }^{3}$ Chao Family Comprehensive Cancer Center, Irvine, California, 92697 USA \\ ${ }^{4}$ Department of Biostatistics, University of Washington, Seattle, Washington, 98195 USA \\ ${ }^{5}$ Rochester General Hospital, Rochester, New York, 14621 USA \\ ${ }^{6}$ QIMR Berghofer Medical Research Institute, Brisbane City, QLD 4006, Australia \\ ${ }^{7}$ Faculty of Medicine and Biomedical Sciences, The University of Queensland, Herston, QLD \\ 4006, Australia \\ ${ }^{8}$ Department of Medicine, London Health Sciences Centre, London, Ontario, N6A 5W9, Canada \\ ${ }^{9}$ Centre for MEGA Epidemiology, The University of Melbourne, Victoria, 3010, Australia \\ ${ }^{10}$ School of Medicine and School of Chemistry and Molecular Bioscience, University of \\ Queensland, Brisbane St. Lucia, QLD 4072, Australia \\ ${ }^{11}$ Royal Brisbane \& Women's Hospital, Herston, QLD 4029, Australia \\ ${ }^{12}$ Murdoch Childrens Research Institute, Parkville Victoria 3052, Australia \\ ${ }^{13}$ Departments of Medicine and Pathology, University of Utah School of Medicine, Salt Lake City, \\ Utah, 84132 USA
}

${ }^{14}$ Division of Hematology and Hematologic Malignancies, University of Utah School of Medicine, Salt Lake City, Utah, 84132 USA

Correspondence: Dr. James C. Barton, 2022 Brookwood Medical Center Drive, Suite 626, Birmingham, AL 35209 USA, Telephone 1.205.877.2888, FAX 1.205.877.2039, ironmd@isp.com.

Author Contributions

J.C.B, G.D.M, and C.E.M contributed equally to this work. J.C.B. conceived the study and drafted the manuscript. J.C.B., P.D.P, P.C.A, L.W.P, V.N.S., and G.D.M. contributed samples and data. W.P.C. tabulated outcomes and performed statistical analyses. D.A.N. supervised exome sequencing. M.J.E. performed statistical genetic analyses. C.E.M, M.J.E., V.N.S, P.D.P., P.C.A, L.C.G, K.J.A., G.A.R., J.D.P., C.J.P., and G.D.M. contributed to the manuscript.

Conflicts of Interests

None of the authors has a conflict of interest to report. 
${ }^{15}$ Department of Veterans Affairs Long Beach Healthcare System, Long Beach, California, 90822 USA

${ }^{16}$ Division of Hematology/Oncology, Department of Medicine, University of California, Irvine, California, 92868 USA

${ }^{17}$ Department of Epidemiology, University of California, Irvine, California, 92697 USA

\section{Abstract}

Background-GNPAT p.D519G positivity is significantly increased in HFE p.C282Y homozygotes with markedly increased iron stores. We sought to determine associations of p.D519G and iron-related variables with iron stores in p.C282Y homozygotes.

Methods-We defined markedly increased iron stores as serum ferritin $>2247 \mathrm{pmol} / \mathrm{L}$ ( $>1000$ $\mu \mathrm{g} / \mathrm{L}$ ) and either hepatic iron $>236 \mu \mathrm{mol} / \mathrm{g}$ dry weight or iron $>10 \mathrm{~g}$ by induction phlebotomy (men and women). We defined normal or mildly elevated iron stores as serum ferritin $<674.1 \mathrm{pmol} / \mathrm{L}$ $\left(<300 \mu \mathrm{g} / \mathrm{L}\right.$ ) or either age $\geq 40 \mathrm{y}$ with iron $\_.5 \mathrm{~g}$ iron by induction phlebotomy or age $250 \mathrm{y}$ with $\$ 3.0 \mathrm{~g}$ iron by induction phlebotomy (men only). We compared participant subgroups using univariate methods. Using multivariable logistic regression, we evaluated associations of markedly increased iron stores with these variables: age; iron supplement use (dichotomous); whole blood units donated; erythrocyte units received as transfusion; daily alcohol consumption, g; and p.D519G positivity (heterozygosity or homozygosity).

Results-The mean age of 56 participants (94.6\% men) was $55 \pm 10$ (SD) y; 41 had markedly increased iron stores. Prevalences of swollen/tender $2 \mathrm{nd} / 3 \mathrm{rd}$ metacarpophalangeal joints and elevated aspartate or alanine aminotransferase were significantly greater in participants with markedly increased iron stores. Only participants with markedly increased iron stores had cirrhosis. In multivariable analyses, p.D519G positivity was the only exposure variable significantly associated with markedly increased iron stores (odds ratio 9.9, 95\% CI [1.6, 60.3], p $=0.0126)$.

Conclusions-GNPAT p.D519G is strongly associated with markedly increased iron stores in p.C282Y homozygotes after correction for age, iron-related variables, and alcohol consumption.

\section{Key words for indexing}

hemochromatosis; iron overload; rs11558492; rs1800562

\subsection{Introduction}

$H F E$ hemochromatosis is an autosomal recessive condition attributed to homozygosity for the p.C282Y mutation (rs1800562) of the HFE gene (chromosome 6p21.3) [1,2]. p.C282Y homozygosity occurs in $0.3-0.6 \%$ of persons of European descent and accounts for $\sim 90 \%$ of hemochromatosis iron phenotypes in whites [2,3]. Decreased hepcidin expression and consequent excessive iron absorption cause iron overload in p.C282Y homozygotes [4], although clinical penetrance of iron overload in many p.C282Y homozygotes is mild [5,6]. Among persons diagnosed to have hemochromatosis and p.C282Y homozygosity in nonscreening venues, the prevalence of iron overload and associated complications such as 
diabetes, other endocrinopathy, cirrhosis, primary liver cancer, and cardiomyopathy is relatively high [3]. In contrast, the results of population screening studies in whites in European and derivative countries reveal that the proportions of p.C282Y homozygotes who have or develop iron overload and related complications varies but is relatively low [5-8]. Thus, p.C282Y homozygosity is necessary but not sufficient to cause hemochromatosis iron phenotypes [9].

Gender, age, diet, and blood loss account in part for iron phenotype variability in persons with hemochromatosis [10-12]. Modifier mutations in non-HFE iron-related genes described to date explain iron phenotype variability in a small proportion of p.C282Y homozygotes [3,13]. Accordingly, it is assumed that other acquired or environmental factors and non-HFE polymorphisms of unreported or unconfirmed effect on iron absorption or iron stores account for much of the remaining unexplained iron phenotype variability among p.C282Y homozygotes [14].

GNPAT (chromosome 1q42.2) encodes the peroxisomal enzyme glyceronephosphate Oacyltransferase [15]. The GNPAT polymorphism p.D519G (rs11558492) is a candidate modifier of iron phenotypes in p.C282Y homozygotes [16,17]. In an initial p.D519G report, we described 35 men with p.C282Y homozygosity who did not report moderate or heavy daily alcohol consumption [16]. Positivity for p.D519G was significantly greater in the 22 men with markedly increased iron stores than in the 13 other men with normal or mildly elevated iron stores [16]. These results suggested that p.D519G modifies iron phenotypes in men with p.C282Y homozygosity without a history of moderate or heavy daily alcohol consumption either by enhancing iron absorption or because p.D519G is linked to a putative iron absorption promoter on chromosome 1q.

To learn more, we evaluated the significance of GNPAT p.D519G as a putative modifier of iron phenotypes in 56 participants with p.C282Y homozygosity who were evaluated with exome sequencing. The present cohort $(\mathrm{n}=56)$ included the original 35 men, of whom 22 had markedly increased iron stores [16], 12 other men (11 of whom had markedly increased iron stores) who were excluded from our initial report because they reported moderate or heavy daily alcohol consumption [16], and 9 additional p.C282Y homozygotes (6 men, 3 women) whose exome sequencing had not been performed at the time of our initial report [16]. Of the 9 additional subjects, 8 had markedly increased iron stores (5 of the 6 men and all 3 women). We applied univariate statistical techniques to compare general observations in the 41 participants with markedly increased iron stores to those of the 15 other participants who had normal or mildly elevated iron stores. Using multivariable statistical techniques, we determined the significance of available variables, including positivity for p.D519G, which could contribute to the development of markedly increased iron stores. We discuss the present results in the context of other reports of p.D519G and iron phenotypes in persons with p.C282Y homozygosity and other HFE genotypes. 


\subsection{Methods}

\subsection{Study performance}

This study was performed in accordance with the Declaration of Helsinki. Approval was obtained from appropriate review boards at: University of California, Irvine; University of Western Ontario; QIMR Berghofer Medical Research Institute; Rochester General Health System; the Cancer Council Victoria; and Department of Veterans Affairs Long Beach Healthcare System. Written informed consent was obtained from all participants. Consortium study sites identified p.C282Y homozygotes in clinical practice settings associated with the investigators or by population screening through the Hemochromatosis and Iron Overload Screening (HEIRS) Study and a study of the Prevalence of Iron Overload and Frequency of the Hemochromatosis Gene conducted at the Department of Veterans Affairs Long Beach Healthcare System.

\subsection{Clinical and laboratory data collection}

Information on demographics, blood donation, alcohol consumption, clinical observations, biochemical tests, and interpretation of liver biopsy specimens was obtained from medical records of participants identified through clinical practices and from the National Institutes of Health BioLincc biorepository for HEIRS Study participants [16]. Observations recorded at diagnosis of hemochromatosis included: age; sex; diabetes diagnoses; use of iron supplements; lifetime units of whole blood donation; lifetime units of erythrocytes received as transfusion; estimated daily alcohol consumption, g; body mass index; swollen/tender 2nd/3rd metacarpophalangeal joints; serum levels of alanine aminotransferase (ALT) and aspartate aminotransferase (AST); and biopsy-proven cirrhosis. Elevated ALT and AST was defined as $>0.67 \mu \mathrm{kat} / \mathrm{L}(>40 \mathrm{IU} / \mathrm{L})$ for both.

\subsection{Exome sequencing}

Quality control of sample DNA, exome capture and sequencing, and performance of sequence kernel association tests were performed at the University of Washington (Seattle, WA) as described in detail elsewhere [18].

\subsection{Participant selection}

Inclusion criteria included: 1) p.C282Y homozygosity confirmed at exome sequencing; 2) participant was unrelated to other participants; 3) participant did not withdraw consent; and 4) participant did not refuse blood storage. Participants with markedly increased iron stores included men and women. By design, all participants with normal or mildly elevated iron stores were men, in order to avoid possible confounding effects of unquantifiable iron losses in women [16]. The participant selection schema is displayed in Fig. 1.

\subsection{Classification of iron phenotypes}

Induction phlebotomy was defined as the amount of iron removed to achieve serum ferritin (SF) $<112.4 \mathrm{pmol} / \mathrm{L}(<50 \mu \mathrm{g} / \mathrm{L})$ [19]. Criteria for markedly increased iron stores were: SF $>2247 \mathrm{pmol} / \mathrm{L}(>1000 \mu \mathrm{g} / \mathrm{L})$ at diagnosis and either hepatic iron $>236 \mu \mathrm{mol} / \mathrm{g}$ dry weight or iron $>10 \mathrm{~g}$ by induction phlebotomy [20]. Criteria for normal or mildly elevated iron stores 
were: $\mathrm{SF}<674.1 \mathrm{pmol} / \mathrm{L}(<300 \mu \mathrm{g} / \mathrm{L})$ or either age $\_40 \mathrm{y}$ with iron $\_.5 \mathrm{~g}$ iron by induction phlebotomy or age $250 \mathrm{y}$ with $3.0 \mathrm{~g}$ iron by induction phlebotomy [16].

\subsection{Statistics}

We used observations for 56 participants in the present analyses. For one participant who reported having received erythrocyte transfusions of unknown number, we imputed a value of one unit of erythrocyte transfusion. Descriptive data are displayed as enumerations, percent (n), mean \pm 1 standard deviation (SD), or odds ratios with $95 \%$ confidence limits obtained by inverting the Wald Test of the null hypothesis. To compare characteristics of those with markedly increased iron stores to those of participants with normal or mildly elevated iron stores we used Fisher's exact test and the Wilcoxon Rank-Sum test, as appropriate, and also applied univariate logistic regression models. We used multivariable logistic regression to estimate the magnitude of the association between markedly increased iron stores (dependent variable) and exposure variables that could influence iron phenotypes: age at diagnosis; use of iron supplements (dichotomous); units of whole blood donation; units of erythrocytes received as transfusion; estimated daily alcohol consumption, g; and positivity for GNPAT p.D519G (heterozygosity or homozygosity). We used SAS® v.9.4 (Statistical Analysis System, Cary, NC).

\subsection{Results}

\subsection{General characteristics of participants}

There were 56 participants (94.6\% men); 55 participants were white and one was African American. Mean age at hemochromatosis diagnosis was $55 \pm 10$ (SD) y. Forty-one participants $(73.2 \%)$ were classified as having markedly increased iron stores. Seven participants $(12.5 \%)$ were diagnosed to have diabetes. Use of iron supplements was reported by 12 participants (21.4\%). Mean units of blood donation was $4 \pm 9$ (range $0-50$ ). Six participants $(10.7 \%)$ reported that they had received erythrocyte transfusion.

Mean estimated daily alcohol consumption was $8 \pm 15 \mathrm{~g}$ (range $0-75$ ). Mean body mass index was $28.0 \pm 5.2 \mathrm{~kg} / \mathrm{m}^{2}$ (range $18.5-47.2$ ). Swelling and/or tenderness of the $2 \mathrm{nd} / 3 \mathrm{rd}$ metacarpophalangeal joints was reported in 23 participants (41.8\%). Elevated ALT and AST levels at diagnosis were observed in 27 participants (51.9\%) and 23 participants (41.8\%), respectively. GNPAT p.D519G was detected in 26 participants (3 homozygotes, 23 heterozygotes). One woman was a GNPATp.D519G heterozygote and the other two women were negative for p.D519G.

\subsection{Participants with and without markedly increased iron stores}

SF values in the two iron phenotype groups are displayed in Table 1. Comparisons of general characteristics between the two phenotype groups are displayed in Table 2. Prevalences of swollen/tender 2nd/3rd metacarpophalangeal joints, elevated ALT, and elevated AST were greater in participants with markedly increased iron stores (Table 2). Cirrhosis was diagnosed in $40.5 \%$ of 37 participants with markedly increased iron stores who underwent liver biopsy. Two participants with normal or mildly elevated iron stores who underwent liver biopsy did not have cirrhosis. Positivity for GNPATp.D519G was 
greater in participants with markedly increased iron stores (Table 2). Twelve participants were excluded from the original study because they reported moderate/heavy alcohol consumption. Eleven had markedly increased iron stores and five of the eleven had p.D519G (3 heterozygotes, 2 homozygotes). The one patient without markedly increased iron stores was a p.D519G heterozygote.

\subsection{Logistic regression on markedly increased iron stores}

We evaluated these variables as possible contributors to markedly increased iron stores: age at diagnosis; use of iron supplements; whole blood units donated; units of erythrocytes received as transfusion; estimated daily alcohol consumption, g; and GNPAT p.D519G positivity (heterozygosity or homozygosity). The odds of participants with p.D519G positivity having markedly increased iron stores were 9.2 times higher $(95 \% \mathrm{CI}[1.8,46.1])$ than those of participants without p.D519G (Table 3). In a multivariable model, p.D519G positivity was significantly associated with markedly increased iron stores (odds ratio 9.9, 95\% CI [1.6, 60.3], $\mathrm{p}=0.0126$ ). There was no significant association of other exposure variables with markedly increased iron stores. The area under the curve for the multivariable logistic regression model was 0.82 .

\subsection{Discussion}

GNPAT p.D519G positivity (or a putative linked allele on chromosome 1q) could account for increased iron absorption in p.C282Y homozygotes with markedly increased iron stores. The present results confirm and extend observations in an initial phase of this study from univariate analyses of p.D519G allele frequency in smaller subsets of men classified by iron stores as defined herein [16]. The present findings are also consistent with observations that p.D519G positivity detected by SNP analysis was significantly associated with increased iron stores ( $>5 \mathrm{~g}$ mobilized within the first year of phlebotomy therapy) in univariate and multiple regression models of observations in p.C282Y homozygotes in southern France [17]. The allele frequency of GNPAT p.D519G (rs11558492) was also significantly greater in 77 unrelated French men with p.C282Y/p.H63D and severe iron phenotypes than in two European population control cohorts [21].

GNPAT p.D519G positivity detected by SNP analysis was not significantly associated with increased iron stores represented by SF or quantities of iron removed by phlebotomy to achieve iron depletion in a large cohort of unselected p.C282Y homozygotes in northern France [22] and in 26 Canadian p.C282Y homozygotes [23] and was not associated with SF $\geq 247 \mathrm{pmol} / \mathrm{L}$ ( $\geq 1000 \mu \mathrm{g} / \mathrm{L}$ ) at diagnosis in Irish or Canadian p.C282Y homozygotes [23,24]. Analyses of observations in subgroups of men in two reports also yielded negative results [22,24]. In one report, SF $2247 \mathrm{pmol} / \mathrm{L}(>1000 \mu \mathrm{g} / \mathrm{L}$ ) at diagnosis was the only definition of increased iron stores [24], unlike the more stringent definitions of markedly increased and normal or mildly elevated iron stores used in our initial-phase study [16], in a confirmatory investigation [17], and in the present study. SF is a surrogate measure of storage iron and diverse non-iron conditions [25]. Comparison of SF levels at diagnosis with quantities of iron removed by phlebotomy to achieve iron depletion in 54 p.C282Y 
homozygotes revealed that "the SF level does provide some information regarding total iron burden but even in the case of C282Y homozygotes, the correlation is not very strong" [26].

The prevalence of swollen/tender metacarpophalangeal joints, a proxy for hemochromatosis hand arthropathy [3], was significantly greater in the present participants with markedly increased iron stores. This is consistent with a report that the prevalence of hand arthropathy is greater in p.C282Y homozygotes with SF >2247 pmol/L (>1000 $\mu \mathrm{g} / \mathrm{L})$ [27]. The proportion of participants with markedly increased iron stores who had elevated AST was significantly higher than that of participants with normal or mildly elevated iron stores. Elevated AST in patients with hemochromatosis and iron overload is generally interpreted to be a consequence of hepatic injury, especially cirrhosis [28,29]. Cirrhosis was diagnosed in $41 \%$ of the 37 present participants with markedly increased iron stores who underwent liver biopsy, consistent with the association of cirrhosis and markedly elevated hepatic iron concentrations in other white adults with hemochromatosis who did not have alcoholism [30].

Use of iron supplements was reported by more than $20 \%$ of the present participants, consistent with a survey of a large number of hemochromatosis patients [31]. Whether ingestion of supplemental inorganic iron increases iron overload severity in typical p.C282Y homozygotes is controversial. The present analyses did not detect a significant association of reports of supplemental iron use with markedly increased iron stores. In 213 screening p.C282Y homozygotes, no significant relationship between reports of supplemental iron use and SF levels was found [32]. In an unusual case, a man with hemochromatosis, p.C282Y homozygosity, and $\beta$-thalassemia minor who ingested ferrous sulfate tablets daily absorbed much iron [33].

The number of units of whole blood donated in a lifetime was not significantly associated with iron phenotype classification of the present participants. In a previous study of 124 nonscreening hemochromatosis probands with p.C282Y homozygosity, numbers of units of whole blood donated before diagnosis were not significantly related to the numbers of units of therapeutic phlebotomy required to achieve iron depletion [34]. In another study, there was no significant difference in self-reported initial mean SF levels between non-screening hemochromatosis probands with p.C282Y homozygosity who were volunteer blood donors before diagnosis and those who were not [35]. In the present study and in previous reports $[34,35]$, the proportions of persons who donated blood before hemochromatosis diagnoses were small.

Twelve of the present men reported former or current moderate or heavy daily alcohol consumption at the time of enrollment in our original study [16]. They were excluded from the original analyses because it was postulated that their alcohol consumption may have modified their iron phenotypes [16]. The strong univariate association of p.D519G positivity with markedly increased iron stores in the present study is consistent with our original report [16], from which the same 12 subjects with moderate or heavy alcohol consumption were excluded. In a review of three large studies of patients with classic hemochromatosis or hemochromatosis with p.C282Y homozygosity, Fletcher and Powell concluded that it was unlikely that heavy alcohol consumption increased either dietary iron intake or iron 
absorption [36]. In $129 \times 1 / \mathrm{SvJ}$ mice with wild-type $H f$ genotypes, alcohol treatment increased iron absorption significantly, whereas heterozygosity or homozygosity for a Hfe knockout abrogated the alcohol-induced iron absorption response [37]. It was deduced that either the Hfe knockout causes maximal suppression of hepcidin levels or Hfe is a component of a pathway utilized by alcohol to decrease hepcidin production and increase iron absorption [37]. Alcohol treatment did not enhance the iron absorption of C57BL/6J and AKR/J mice [37].

Alcohol can be hepatotoxic. It was estimated that the daily consumption of $30 \mathrm{~g}[38,39]$ or $>60 \mathrm{~g}[36,40]$ of alcohol can worsen iron-related liver injury. In persons with cirrhosis, daily consumption of these amounts of alcohol may also increase the risk of hepatocellular carcinoma [36,39]. Persons with hepatic injury due to iron overload associated with hemochromatosis may benefit by abstaining from consuming alcohol.

Limitations of the present study include the small number of women with markedly increased iron stores whose data were available for analysis. Thus, it is unknown whether GNPAT p.D519G positivity would be significantly associated with markedly increased iron stores in a larger cohort that included more women. The doses and schedules of supplemental iron ingested and durations of supplemental iron use by the present participants are unknown. Although GNPAT siRNA treatment markedly decreased hepcidin expression in HepG2/C3A cells [16], the mechanism(s) by which p.D519G (or a putative linked allele on chromosome 1q) promotes iron absorption in white p.C282Y homozygotes $[16,17]$ and in French men with p.C282Y/p.H63D and severe iron phenotypes [21] or increases serum iron levels in Taiwanese women without p.C282Y [41] has not been reported.

\section{Conclusions}

GNPAT p.D519G is strongly associated with markedly increased iron stores in p.C282Y homozygotes after correction for age, iron-related exposure variables, and alcohol consumption.

\section{Acknowledgments}

The authors recognize and appreciate financial support in part by grant 1R24DK093433-01 from the National Institute of Diabetes and Digestive and Kidney Diseases, grant P30 CA-62203 from the National Cancer Institute, and funds from the Department of Veterans Affairs. V.N.S., G.A.R., and G.J.A. are supported by Senior Research Fellowships from the NHMRC of Australia. J.C.B. is supported in part by Southern Iron Disorders Center.

\section{Abbreviations}
ALT
alanine aminotransferase
AST
aspartate aminotransferase
SD
standard deviation
SF
serum ferritin 


\section{References}

1. Saddi R, Feingold J. Idiopathic haemochromatosis: an autosomal recessive disease. Clin Genet. 1974; 5:234-241. [PubMed: 4838891]

2. Feder JN, Gnirke A, Thomas W, Tsuchihashi Z, Ruddy DA, Basava A, Dormishian F, Domingo R Jr, Ellis MC, Fullan A, Hinton LM, Jones NL, Kimmel BE, Kronmal GS, Lauer P, Lee VK, Loeb DB, Mapa FA, McClelland E, Meyer NC, Mintier GA, Moeller N, Moore T, Morikang E, Prass CE, Quintana L, Starnes SM, Schatzman RC, Brunke KJ, Drayna DT, Risch NJ, et al. A novel MHC class I-like gene is mutated in patients with hereditary haemochromatosis. Nat Genet. 1996; 13:399-408. [PubMed: 8696333]

3. Edwards, CQ., Barton, JC. Hemochromatosis. In: Greer, JP.Arber, DA.Glader, B.List, AF.Means, RT., JrParaskevas, F., et al., editors. Wintrobe's Clinical Hematology. 13th ed. 13. Philadelphia: Wolters Kluwer/Lippincott Williams \& Wilkins; 2014. p. 662-681.

4. Nemeth E, Ganz T. The role of hepcidin in iron metabolism. Acta Haematol. 2009; 122:78-86. [PubMed: 19907144]

5. Allen KJ, Gurrin LC, Constantine CC, Osborne NJ, Delatycki MB, Nicoll AJ, McLaren CE, Bahlo M, Nisselle AE, Vulpe CD, Anderson GJ, Southey MC, Giles GG, English DR, Hopper JL, Olynyk JK, Powell LW, Gertig DM. Iron-overload-related disease in HFE hereditary hemochromatosis. N Engl J Med. 2008; 358:221-230. [PubMed: 18199861]

6. McLaren GD, McLaren CE, Adams PC, Barton JC, Reboussin DM, Gordeuk VR, Acton RT, Harris EL, Speechley MR, Sholinsky P, Dawkins FW, Snively BM, Vogt TM, Eckfeldt JH. Clinical manifestations of hemochromatosis in HFE $\mathrm{C} 282 \mathrm{Y}$ homozygotes identified by screening. Can J Gastroenterol. 2008; 22:923-930. [PubMed: 19018338]

7. Åsberg A, Hveem K, Thorstensen K, Ellekjter E, Kannelonning K, Fjosne U, Halvorsen TB, Smethurst HB, Sagen E, Bjerve KS. Screening for hemochromatosis: high prevalence and low morbidity in an unselected population of 65,238 persons. Scand J Gastroenterol. 2001; 36:11081115. [PubMed: 11589387]

8. Beutler E, Felitti VJ, Koziol JA, Ho NJ, Gelbart T. Penetrance of 845G->A (C282Y) HFE hereditary haemochromatosis mutation in the USA. Lancet. 2002; 359:211-218. [PubMed: 11812557]

9. Beutler E. Penetrance of haemochromatosis. Gut. 2003; 52:610-611.

10. Adams PC, Deugnier Y, Moirand R, Brissot P. The relationship between iron overload, clinical symptoms, and age in 410 patients with genetic hemochromatosis. Hepatology. 1997; 25:162-166. [PubMed: 8985284]

11. Bothwell, TH., Charlton, RW., Cook, JD., Finch, CD. Iron Metabolism in Man. Oxford: Blackwell Scientific Publications; 1979.

12. Moirand R, Adams PC, Bicheler V, Brissot P, Deugnier Y. Clinical features of genetic hemochromatosis in women compared with men. Ann Intern Med. 1997; 127:105-110. [PubMed: 9229998]

13. Barton JC, Edwards CQ, Acton RT. HFE gene: Structure, function, mutations, and associated iron abnormalities. Gene. 2015; 574:179-192. [PubMed: 26456104]

14. McLaren CE, Barton JC, Eckfeldt JH, McLaren GD, Acton RT, Adams PC, Henkin LF, Gordeuk VR, Vulpe CD, Harris EL, Harrison BW, Reiss JA, Snively BM. Heritability of serum iron measures in the Hemochromatosis and Iron Overload Screening (HEIRS) family study. Am J Hematol. 2010; 85:101-105. [PubMed: 20095037]

15. Thai TP, Rodemer C, Jauch A, Hunziker A, Moser A, Gorgas K, Just WW. Impaired membrane traffic in defective ether lipid biosynthesis. Hum Mol Genet. 2001; 10:127-136. [PubMed: 11152660]

16. McLaren CE, Emond MJ, Subramaniam VN, Phatak PD, Barton JC, Adams PC, Goh JB, McDonald CJ, Powell LW, Gurrin LC, Allen KJ, Nickerson DA, Louie T, Ramm GA, Anderson GJ, McLaren GD. Exome sequencing in HFE C282Y homozygous men with extreme phenotypes identifies a GNPAT variant associated with severe iron overload. Hepatology. 2015; 62:429-439. [PubMed: 25605615] 
17. Besson-Fournier C, Martinez M, Vinel JP, Aguilar-Martinez P, Coppin H, Roth MP. Further support for the association of GNPAT variant rs 11558492 with severe iron overload in hemochromatosis. Hepatology. 2015

18. McLaren CE, Barton JC, Subramaniam VN, Ramm GA, Phatak PD, Emond MJ, Gurrin LC, Adams PC, Powell LW, Anderson GJ, McLaren GD. Reply. Hepatology. 2016

19. Adams PC, Barton JC. How I treat hemochromatosis. Blood. 2010; 116:317-325. [PubMed: 20308595]

20. Powell LW, Dixon JL, Ramm GA, Purdie DM, Lincoln DJ, Anderson GJ, Subramaniam VN, Hewett DG, Searle JW, Fletcher LM, Crawford DH, Rodgers H, Allen KJ, Cavanaugh JA, Bassett ML. Screening for hemochromatosis in asymptomatic subjects with or without a family history. Arch Intern Med. 2006; 166:294-301. [PubMed: 16476869]

21. Tachon G, Roth M-P, Calcoen F, Besson-Fournier C, Bismuth M, Aguilar-Martinez P. Phenotypic variability in genetic hemochromatosis: study of five SNPs in a cohort of 342 compound heterozygotes for the HFE Cys282Tyr/His63Asp mutations. Blood. 2015; 126:3361.

22. Bardou-Jacquet E, de Tayrac M, Mosser J, Deugnier Y. GNPAT variant associated with severe iron overload in HFE hemochromatosis. Hepatology. 2015; 62:1917-1918. [PubMed: 25891252]

23. Levstik A, Stuart A, Adams PC. GNPAT variant (D519G) is not associated with an elevated serum ferritin or iron removed by phlebotomy in patients referred for C282Y-linked hemochromatosis. Ann Hepatol. 2016; 15:907-910. [PubMed: 27740525]

24. Ryan E, Russell J, Ryan JD, Crowe J, Stewart S. GNPAT variant is not associated with severe iron overload in Irish C282Y homozygotes. Hepatology. 2015

25. Lipschitz DA, Cook JD, Finch CA. A clinical evaluation of serum ferritin as an index of iron stores. N Engl J Med. 1974; 290:1213-1216. [PubMed: 4825851]

26. Beutler E, Felitti V, Ho NJ, Gelbart T. Relationship of body iron stores to levels of serum ferritin, serum iron, unsaturated iron binding capacity and transferrin saturation in patients with iron storage disease. Acta Haematol. 2002; 107:145-149. [PubMed: 11978935]

27. Valenti L, Fracanzani AL, Rossi V, Rampini C, Pulixi E, Varenna M, Fargion S, Sinigaglia L. The hand arthropathy of hereditary hemochromatosis is strongly associated with iron overload. J Rheumatol. 2008; 35:153-158. [PubMed: 18061976]

28. Lin E, Adams PC. Biochemical liver profile in hemochromatosis. A survey of 100 patients. J Clin Gastroenterol. 1991; 13:316-320. [PubMed: 2066547]

29. Brissot P, Guyader D, Loreal O, Laine F, Guillygomarc'h A, Moirand R, Deugnier Y. Clinical aspects of hemochromatosis. Transfus Sci. 2000; 23:193-200. [PubMed: 11099895]

30. Bassett ML, Halliday JW, Powell LW. Value of hepatic iron measurements in early hemochromatosis and determination of the critical iron level associated with fibrosis. Hepatology. 1986; 6:24-29. [PubMed: 3943787]

31. McDonnell SM, Grindon AJ, Preston BL, Barton JC, Edwards CQ, Adams PC. A survey of phlebotomy among persons with hemochromatosis. Transfusion. 1999; 39:651-656. [PubMed: 10378847]

32. Gordeuk VR, Lovato L, Barton J, Vitolins M, McLaren G, Acton R, McLaren C, Harris E, Speechley M, Eckfeldt JH, Diaz S, Sholinsky P, Adams P. Dietary iron intake and serum ferritin concentration in 213 patients homozygous for the HFE C282Y hemochromatosis mutation. Can J Gastroenterol. 2012; 26:345-349. [PubMed: 22720276]

33. Barton JC, Lee PL, West C, Bottomley SS. Iron overload and prolonged ingestion of iron supplements: clinical features and mutation analysis of hemochromatosis-associated genes in four cases. Am J Hematol. 2006; 81:760-767. [PubMed: 16838333]

34. Barton JC, Preston BL, McDonnell SM, Rothenberg BE. Severity of iron overload in hemochromatosis: effect of volunteer blood donation before diagnosis. Transfusion. 2001; 41:123129. [PubMed: 11161257]

35. Power TE, Adams PC. Hemochromatosis patients as voluntary blood donors. Can J Gastroenterol. 2004; 18:393-396. [PubMed: 15190395]

36. Fletcher LM, Powell LW. Hemochromatosis and alcoholic liver disease. Alcohol. 2003; 30:131136. [PubMed: 12957297] 
37. Flanagan JM, Peng H, Beutler E. Effects of alcohol consumption on iron metabolism in mice with hemochromatosis mutations. Alcohol Clin Exp Res. 2007; 31:138-143. [PubMed: 17207112]

38. LeSage GD, Baldus WP, Fairbanks VF, Baggenstoss AH, McCall JT, Moore SB, Taswell HF, Gordon H. Hemochromatosis: genetic or alcohol-induced? Gastroenterology. 1983; 84:1471-1477. [PubMed: 6840475]

39. Deugnier YM, Guyader D, Crantock L, Lopez JM, Turlin B, Yaouanq J, Jouanolle H, Campion JP, Launois B, Halliday JW. Primary liver cancer in genetic hemochromatosis: a clinical, pathological, and pathogenetic study of 54 cases. Gastroenterology. 1993; 104:228-234. [PubMed: 8419246]

40. Fletcher LM, Dixon JL, Purdie DM, Powell LW, Crawford DH. Excess alcohol greatly increases the prevalence of cirrhosis in hereditary hemochromatosis. Gastroenterology. 2002; 122:281-289. [PubMed: 11832443]

41. Hsiao SC, Lee CT, Pei SN. GNPAT variant is associated with iron phenotype in healthy Taiwanese women: A population without the HFE C282Y mutation. Hepatology. 2016 
PARTICIPANT SELECTION

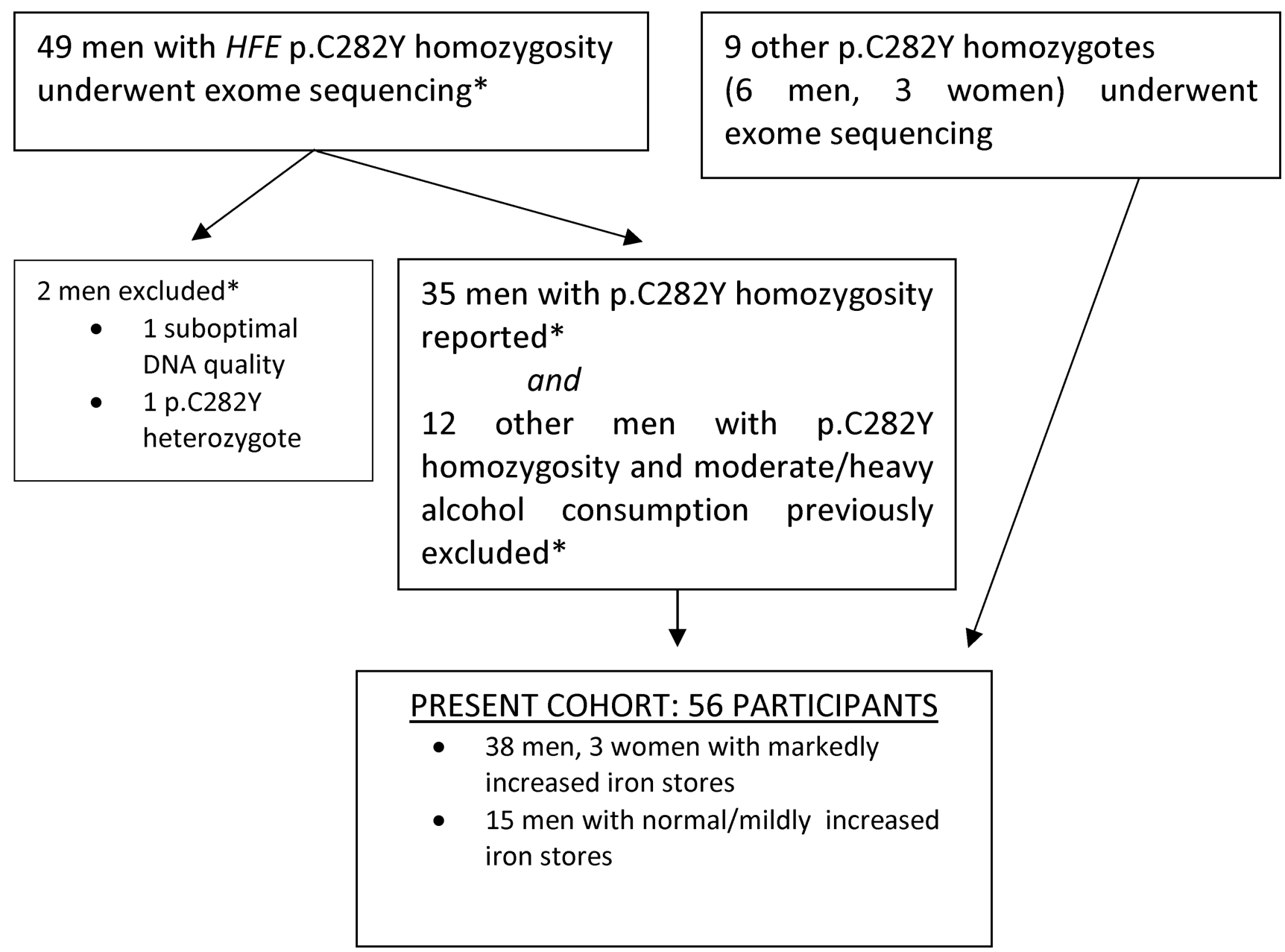

Fig. 1.

Schema of participant selection. Asterisk refers to McLaren CE et al. Hepatology 2015; 62: 429-439 [16]. Exome sequencing of the DNA of the nine additional participants (6 men, 3 women) was performed after out report of the initial 49 men [16]. 


\section{Table 1}

Serum ferritin (SF) levels at diagnosis in 56 p.C282Y homozygotes ${ }^{1}$

\begin{tabular}{llll}
\hline Iron phenotype (n) & $\begin{array}{l}\text { Median SF, } \\
\mathbf{p m o l} / \mathbf{L}(\boldsymbol{\mu g} / \mathbf{L})\end{array}$ & $\begin{array}{l}\boldsymbol{e}^{\text {Mean }} \mathbf{S F}^{2}[\mathbf{9 5 \%} \text { confidence } \\
\text { interval], pmol/L ( } \boldsymbol{\mu g} / \mathbf{L})\end{array}$ & $\begin{array}{l}\text { Range, } \\
\mathbf{p m o l} / \mathbf{L}(\boldsymbol{\mu g} / \mathbf{L})\end{array}$ \\
Markedly increased iron stores (41) & $6265(2788)$ & $6184[5218,7256](2752[2322,3229])$ & $2337-20794(1040-9254)$ \\
Normal or mildly elevated iron stores (15) & $710(316)$ & $679[431,1063](302[192,473])$ & $148-1849(66-823)$ \\
\hline
\end{tabular}

${ }^{1}$ Criteria for markedly increased iron stores were: SF $>2247 \mathrm{pmol} / \mathrm{L}(>1000 \mu \mathrm{g} / \mathrm{L})$ at diagnosis and either hepatic iron $>236 \mu \mathrm{mol} / \mathrm{g}$ dry weight or iron $>10 \mathrm{~g}$ by induction phlebotomy. Criteria for normal or mildly elevated iron stores were: SF $<674.1 \mathrm{pmol} / \mathrm{L}(<300 \mu \mathrm{g} / \mathrm{L})$ or either age $\geq 40 \mathrm{y}$ with iron $\mathcal{S} .5 \mathrm{~g}$ iron by induction phlebotomy or age $\geq 50 \mathrm{y}$ with $\leq 3.0 \mathrm{~g}$ iron by induction phlebotomy.

${ }^{2}$ SF values are not normally distributed. Thus, we computed the means of $\log _{e} S F$ values and corresponding $95 \%$ confidence intervals and display the corresponding antilogse. 


\section{Table 2}

Characteristics of 56 HFE p.C282Y homozygotes ${ }^{1}$

\begin{tabular}{|c|c|c|c|}
\hline Characteristic & $\begin{array}{l}\text { Markedly increased } \\
\text { iron stores } \\
(\mathbf{n}=\mathbf{4 1})\end{array}$ & $\begin{array}{l}\text { Normal or mildly } \\
\text { elevated iron stores } \\
(\mathbf{n}=15)\end{array}$ & $\begin{array}{l}\text { Value of } \\
\text { p }\end{array}$ \\
\hline Mean age, y (SD) & $54(10.6)$ & $57(9.6)$ & $0.57^{3}$ \\
\hline Male, \% (n) & $93(38)$ & $100(15)$ & $0.56^{4}$ \\
\hline Use of iron supplements, \% (n) & $15(6 / 41)$ & $40(6 / 15)$ & $0.064^{4}$ \\
\hline Mean whole blood units donated (SD) & $4.2(9.61)$ & $4.4(7.61)$ & $0.71^{3}$ \\
\hline Mean erythrocyte units received as transfusion (SD) & $0.2(0.99)$ & $0.2(0.56)$ & $0.73^{3}$ \\
\hline Mean estimated daily alcohol consumption, g (SD) & $9.8(17.04)$ & $4.2(7.77)$ & $0.85^{3}$ \\
\hline Diabetes diagnosis, \% (n) & $12(5 / 41)$ & $13(2 / 15)$ & $1.00^{4}$ \\
\hline Mean BMI, $\mathrm{kg} / \mathrm{m}^{2}(\mathrm{SD})$ & $27.9(5.54)$ & $28.5(4.43)$ & $0.63^{3}$ \\
\hline Swollen/tender MCP joints, \% (n) & $56(23 / 41)$ & $0(0 / 14)$ & $0.0001^{4}$ \\
\hline Elevated ALT, \% (n) & $68(25 / 37)$ & $13(2 / 15)$ & $0.001^{4}$ \\
\hline Elevated AST, \% (n) & $57(23 / 40)$ & $0(0 / 15)$ & $<0.0001^{4}$ \\
\hline Positivity for GNPATp.D519G, $\%(\mathrm{n})^{5}$ & $59(24 / 41)$ & $13(2 / 15)$ & $0.003^{4}$ \\
\hline \multicolumn{4}{|c|}{${ }^{1}$ Abbreviations: ALT, alanine aminotransferase; AST, aspartate aminotransferase; BMI, body mass index; MCP, metacarpophalangeal. } \\
\hline \multicolumn{4}{|c|}{$\begin{array}{l}2 \text { Markedly increased iron stores: } \mathrm{SF}>2247 \mathrm{pmol} / \mathrm{L}(>1000 \mu \mathrm{g} / \mathrm{L} \text { ) at diagnosis and either hepatic iron concentration }>236 \mu \mathrm{mol} / \mathrm{g} \text { dry weight } \\
\text { (reference range } 0-36 \mu \mathrm{mol} / \mathrm{g} \text { ) or mobilized body iron }>10 \mathrm{~g} \text { by induction phlebotomy. Normal or mildly elevated iron stores: } \mathrm{SF}<674.1 \mathrm{pmol} / \mathrm{L} \\
\left(<300 \mu \mathrm{g} / \mathrm{L} \text { ) or either age } \geq 40 \mathrm{y} \text { with } \_.5 \mathrm{~g} \text { iron by induction phlebotomy, or age } \geq 50 \mathrm{y} \text { with } \_3.0 \mathrm{~g} \text { iron by induction phlebotomy. }\right.\end{array}$} \\
\hline \multicolumn{4}{|c|}{${ }^{3}$ Wilcoxon Rank-Sum test. } \\
\hline${ }^{4}$ Fisher's exact test. & & & \\
\hline
\end{tabular}




\section{롤 \\ ํㅗㄹ}

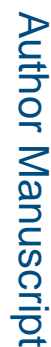

年

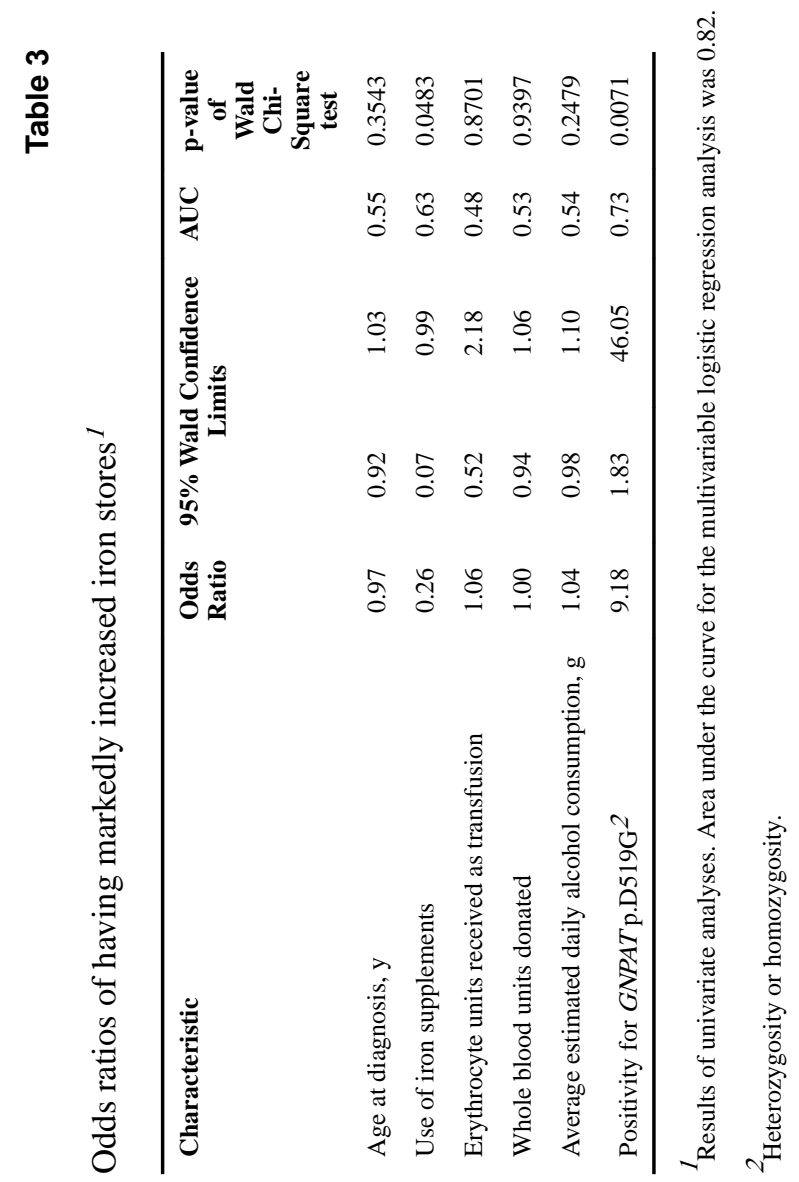

Blood Cells Mol Dis. Author manuscript; available in PMC 2018 March 01. 